\title{
SEED BANK DYNAMICS OF KEKILLA FERNLANDS AND ABANDONED CHENA UNDER PARTIAL SHADE AND FULL SUN CONDITIONS
}

\author{
M C Devendra and B M P Singhakumara \\ Department of Forestry and Environmental Science \\ University of Sri Jayewardenepura, Nugegoda
}

Seed bank dynamics can be considered an important component of the regeneration of individual plant populations and communities. Soil seed bank dynamics in Kekilla fernlands and abandoned chena need to be studied as possible sources of regeneration for forest restoration of degraded lands.

This study was done to understand regeneration dynamics of soil seed banks with reference to two light regimes in Kekilla fernlands and abandoned chena in the periphery of Sinharaja World Heritage Site.

Sinharaja World Heritage Site is one of the least disturbed and biologically unique lowland rain forests now remaining in Sri Lanka. Today some areas of the periphery of Sinharaja are covered with secondary scrub and Kekilla (Dicranopteris linearis) fernlands. Three sites of Kekilla fernlands and three sites of abandoned chena were selected for the study.

Four soil samples were purposively collected from four different locations in each site. These four samples were pooled and mixed in a polythene bag. Eight trays were prepared using one mixture of soil from one site. Four trays from each site were placed under partial shade $\left(750 \mu \mathrm{mol} \mathrm{m}^{-2} \mathrm{~s}^{-1}\right)$ and others were placed under full sunlight $\left(2000 \mu \mathrm{mol} \mathrm{m}^{-2}\right.$ $\mathrm{s}^{-1}$ ). Seeds inside the soils were allowed to germinate. Newly germinated seeds were recorded every fifth day. All germinated seeds that were able to be identified were removed and counted once a month.

Seedlings of 45 taxa were identified during the period of study. Among the counted seedlings a larger proportion was recruited under the partial shade treatment than full sun treatment. Results indicate that the number of species germinated from abandoned chena was greater than that of Kekilla fernlands. Finding suggest that in all treatments only pioneer species germinated. Climax species were not represented in any of the sites or light treatments.

Proceedings of the Third Annual Forestry Symposium 1997, of the Department of Forestry and Environmental Science, University of Sri Jayewardenepura, Sri Lanka 